\title{
Current Status, Requirements and Opportunities for Green Building in Sri Lanka
}

\author{
Guanwardana S.A.A. ${ }^{1}$, Maheepala S.A.D.S.S. ${ }^{1}$, Jayasinghe G.Y. ${ }^{*}$ \\ ${ }^{1}$ Department of Agricultural Engineering, Faculty of Agriculture, University of Ruhuna, Sri Lanka \\ *jayasinghe@ageng.ruh.ac.lk
}

\begin{abstract}
The construction sector is responsible for a large percentage of the world's total energy consumption and greenhouse gas emissions. Therefore, the concept of green building has become one of the effective forefronts for the sustainable development. With the global trend, Sri Lanka also has put the interest on adopting the green concept. This paper examines the current status, opportunities, benefits and challenges in associated with green buildings and a comparison between GREENSL rating system for built environment which is developed by Green Building Council of Sri Lanka (GBCSL) and LEED Leadership in Energy and Environmental Design which is developed by United States Green Building Council(USGBC). Through the concept of green building it provides significant benefits over traditional construction practices. Reducing consumption by incorporating energy and water efficient mechanisms, combining renewable energy, improving indoor air quality and upgrading the health and comfortability of occupants, reduction of waste, reduced life cycle cost (LCC) and increased life span of the building are some of the major drives. However there are some challenges for the implementation of green construction projects. $5-10 \%$ of higher initial costs, fear of unknown, technical difficulties during the construction process, lengthy approval process are some of the main barriers for the widespread of this concept. The quality of green buildings can be assessed by green certifications used in Sri Lanka. When aiming for green building certification, property developers have two crucial options namely LEED and GREENSL. There are 7 criteria under LEED and GREENSL, respectively. Sustainable site, water efficiency, energy and atmosphere, indoor air quality and innovation design are the criteria common to both rating systems. Management and social and cultural awareness are the two criteria additionally used by GREENSL and regional priority is the criterion specific to LEED. By observing these criteria it is evident that both rating systems have common objectives. Comparatively GREENSL has been developed by considering our own requirements. Therefore, it is much more appropriate to Sri Lankan context. Similarly it was observed that the same rating system is used for each and every building type within the construction sector. Considering the facts it can be suggested that different rating systems with different criteria can be developed and use as the structure of the building is different to each other. Meantime it is essential for the government to implement policies to obtain green certification for every structure build in the construction sector.
\end{abstract}

Keywords: GREEN ${ }^{\mathrm{SL}}$, Green Building, Indoor air quality, LEED, Water efficiency

Proceedings of the $22^{\text {nd }}$ International Forestry and Environment Symposium 2017 of the Department of Forestry and Environmental Science, University of Sri Jayewardenepura, Sri Lanka 